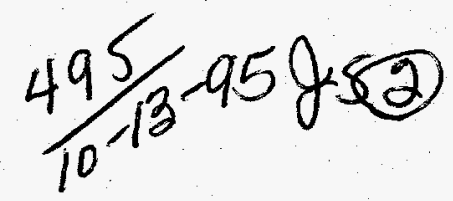

U.S. Department of Energy

\title{
RCRA Corrective Action: Statement of Basis and Response to Comments Decision Documents
}

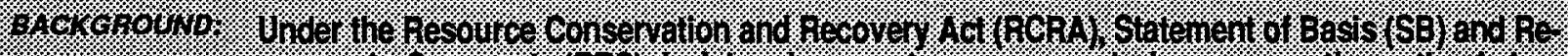

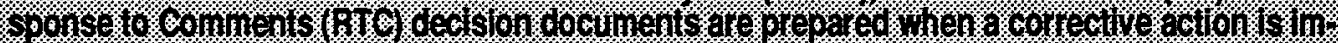

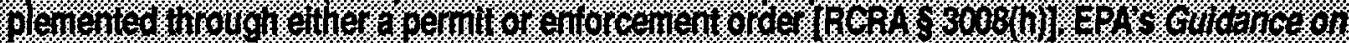

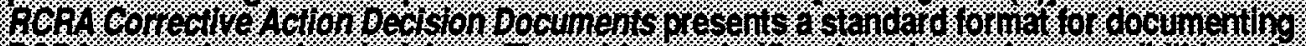

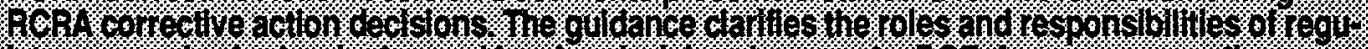

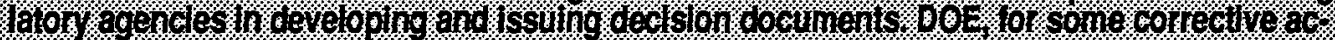

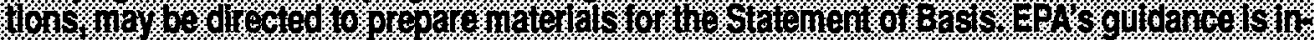

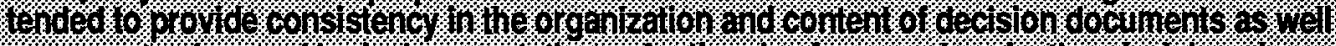

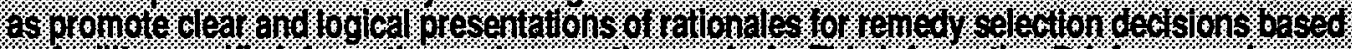

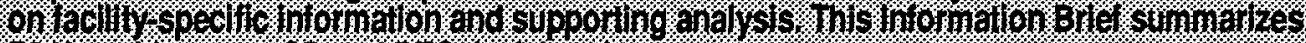

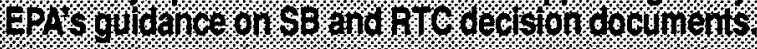

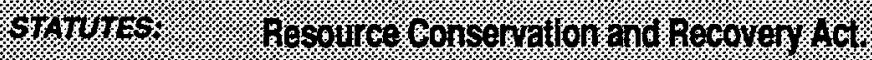

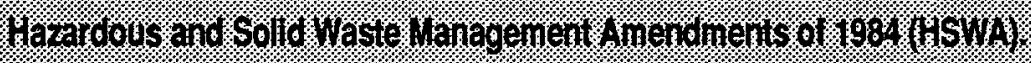

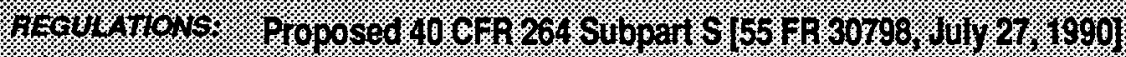
$400 \mathrm{H}$ Ran $12 \%$

$40 \mathrm{CAR} 300$

RERERENCE

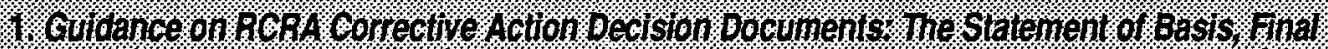

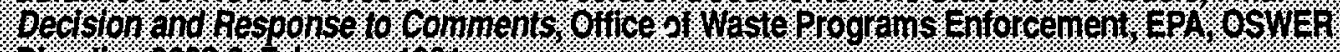
Dliective 9902 6. February 1991 .

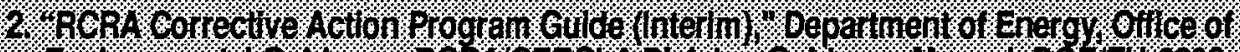

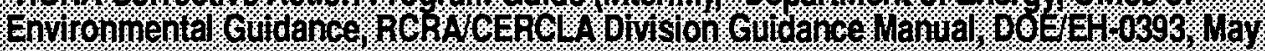
1993

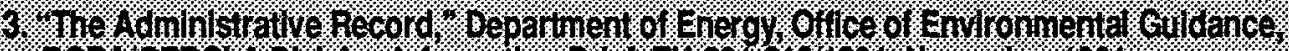

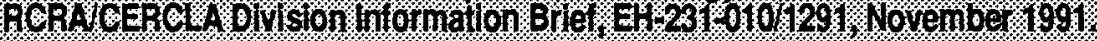

4. The Infornation Repositon y Departinent of Energy, Otice of Envitonnental Guidance.

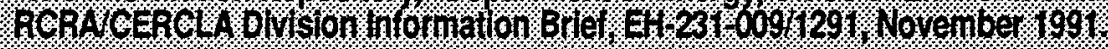

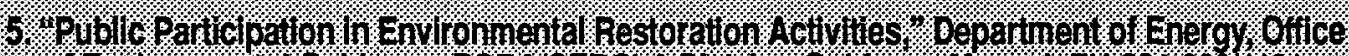

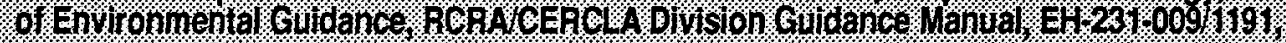
Novenber 1991 .

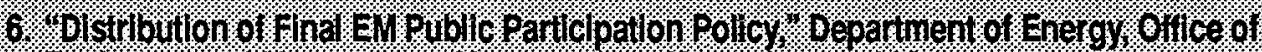
Environmenta/ Hanagenent Memorandum, Hovenber 5.1992 .

\section{What is a "Statement of Basis" decision document?}

An SB is a RCRA corrective action decision document that:

$\square$ identifies the proposed remedy for a corrective action at a facility and explains the reasons for the proposal;

$\square$ describes all remedies that were considered in the RCRA Facility Investigation (RFI) and Corrective Measures Study (CMS) reports; a solicits public review and comments on the remedies considered in the RFI and CMS reports (see reference 2); and

$\checkmark$ provides information on how the public can be involved in the remedy selection process.

The SB is designed to serve as a companion to the RFI/CMS and the administrative record file (see reference 3 ). The remedy proposed in the SB is only an initial recommendation. Public comment and/or additional information may result in changes to the proposed remedy or in the choice of another remedy. 


\section{What information should SBs contain?}

SBs provide a brief summary of all of the altematives studied in the detailed analysis phase of the RFI/CMS, highlighting the key factors that led to the identification of the proposed remedy. The SB should contain the following information:

a facility name and location;

$\checkmark$ document's purpose;

D proposed remedy and how that remedy will protect human health and the environment;

$\checkmark$ brief summary of the RFI and brief description of alternatives evaluated in detail during the CMS;

$\square$ brief overview of the site, including contaminated media, chemicals of concern, baseline exposure scenarios, ecological risks, current and potential risks posed by the facility (including carcinogenic and noncarcinogenic risks), and site history;

a scope of the problem the remedy will address and information regarding how the remedy or each phase of the remedy addresses the problem;

$\square$ criteria used to evaluate the proposed remedy and alternatives;

$\square$ methods that will be used to monitor the remedy's effectiveness;

$\checkmark$ notice of public comment period; time and place for a public meeting(s) or information regarding opportunities for meetings; and previous or ongoing public participation activities and how they impacted the remedy evaluation;

$\checkmark$ location of the administration record files and information repositories (see reference 4) and times that the record is available for review; and

$\square$ name and telephone number of the person to contact for more information.

SBs should be written in a clear and concise manner using nontechnical language. Refer to EPA's Guidance on RCRA Corrective Action Decision Documents for a suggested format for SBs (reference 1).

\section{What evaluation criteria are used in an SB to explain the choice of the proposed remedy?}

The evaluation criteria used to analyze the proposed remedy and altematives encompass four general standards and five selection decision factors that assist in determining the overall effectiveness of the remedial altematives. The four general standards for corrective measures are:

overall protection of human health and the environment,

口 attainment of media cleanup standards,

control of the sources of releases, and

u comparison with standards for management of wastes.

The five selection decision factors are:

口 long-term reliability and effectiveness;

a reduction of toxicity, mobility, or volume of wastes;

口 short-term effectiveness;

$\square$ ease of implementation; and

cost.

\section{How are SBs prepared for a limited scope} remedial action?

Limited scope remedial action is a unique corrective action process caused by insufficient available technology, unusual site conditions, or the nature of the contamination at the site (see reference 1). The unique characteristics of the corrective action limit the scope of what actions can be taken at the site. For example, remediating a contaminated wetland may result in more environmental harm than if the contaminants were left in place. A limited scope remedial action SB must be accompanied by an assurance that the public is protected from exposure to the hazards that are being remediated.

\section{How are SBs prepared for contingency remedies?}

The proposed remedy is usually identified in the SB, and the final remedy is specified in the RTC. However, in some circumstances, a permit modification with a selected remedy accompanied by a contingency remedy may be appropriate to give additional flexibility.

The contingency remedy serves two purposes. First, the additional flexibility promotes the use of innovative treatment technology. The regulatory agency may include a proven technology as a contingency remedy in the SB and draft permit 


\section{DISCLAIMER}

Portions of this document may be illegible in electronic image products. Images are produced from the best available original document. 
modification (where applicable). Second, if two technologies appear to be equally adequate, the SB may identify the proposed remedy and the other as the contingency remedy and specify the criteria whereby the contingency remedy would be implemented.

\section{What is a "Response to Comments" decision document?}

The regulatory agency prepares the RTC at the conclusion of the public comment period. An RTC decision document serves several purposes:

$\square$ identifies the selected remedy;

$\square$ provides information about community preferences regarding the remedial alternatives and general concerns about the facility;

a demonstrates how public comments were integrated into the decision-making process;

$\square$ provides a written record of the regulatory agency's RTC; and

a enables a court or interested party reviewing the selected remedy to determine whether the regulatory agency provided a reasonable corrective action strategy.

An adequate RTC is essential for defending final permit modifications during remedy implementation negotiations or in judicial proceedings.

\section{What information should RTCs contain?}

An RTC provides a concise and complete summary of comments received from the public, including the owner or operator of the facility, and responses to those comments. Responses should be clear, accurate, and carefully written. RTCs should contain the following information:

- the facility name and location;

$\square$ a clear explanation of how the regulatory agency considered and responded to the comments received;

a a brief summary of the major treatment components of the selected remedy and how the selected remedy will provide adequate protection of human health and the environment;

$\square$ an identification of where and when the public meetings took place;

$\square$ a brief description of the comments received on the proposed remedy, RFI, or CMS from other regulatory agencies, local officials, and private citizens;

a a brief discussion of any future action to be taken by the regulatory agency (e.g., post-closure permitting, closure plan approval, etc.) that will be an integral part of the remedy's implementation;

$\checkmark$ the signature of the Regional Administrator, or other person deemed appropriate by the regulatory agency, and the date the document was signed;

Refer to EPA's Guidance on RCRA Corrective Action Decision Documents for a suggested format for RTCs.

\section{How do SBs and RTCs relate to the overall RCRA corrective action process?}

The RCRA corrective action process under proposed 40 CFR 264 Subpart $S$ can be divided into several phases:

口 RCRA Facility Assessment (RFA). During the RFA information is gathered on releases of hazardous wastes or hazardous waste constituents, solid waste management units, and other areas of environmental concern. Preliminary determinations are made regarding releases of hazardous wastes or hazardous waste constituents and the need for future remedial actions at a facility.

口 Interim Measures. The immediacy and magnitude of the potential threat to human health and the environment and the consequences of delayed action may require interim measures. Interim measures do not require an SB.

口 RCRA Facility Investigation (RFI). The owner/operator of the facility under investigation then performs an RFI if the regulatory agency determines it is necessary. The purpose of the RFI is to thoroughly evaluate the nature and extent of releases of hazardous wastes or hazardous constituents from solid waste management units and to gather necessary data to support the CMS. The RFI also includes a comparison of release characterization data and established health and environmental criteria.

- Corrective Measures Study. A CMS is conducted if necessary. During this stage the owner/operator identifies, evaluates, and recommends specific remedies for cleaning up releases of hazardous waste or hazardous constituents based on detailed engineering evaluations of the 
data generated during the RFI, along with information pertaining to potential corrective measures technologies.

口 Statement of Basis and the Public Comment Period for Selection of Remedies. An SB, which contains the regulatory agency's proposed remedy, is then developed and presented during the public comment period. Where applicable, the draft permit modification would also be presented to the public.

口 Responses to Comments. After public comments have been received, the regulatory agency is required to prepare an RTC before the issuance of any final permit decisions pursuant to $40 \mathrm{CFR}$ 124.15.

口 Corrective Measures Implementation. Corrective Measures Implementation includes designing, constructing, operating, maintaining, and monitoring the performance of the remedy selected to protect human health and the environment.

\section{Who is responsible for writing the SB and RTC documents?}

Ultimately, EPA is responsible for ensuring that the SB and RTC are prepared properly for corrective actions at federal facilities and will, more often than not, pursue agreements for DOE to write the SB and RTC pending final approval by EPA. EPA may reject or modify the documents submitted by DOE.

\section{How should public notices be prepared?}

Upon completion of the RFI and CMS, the agency that wrote the SB should prepare a public notice, with the assistance of DOE, announcing the availability of the SB, the RFI/CMS reports, the administrative record, and the draft permit modification (if applicable).

The public notice should include a brief abstract of the SB, which describes the remedial alternatives analyzed during the CMS and identifies the proposed remedy. A public notice of permit actions must be prepared in accordance with 40 CFR 124.10 (d). A public notice prepared for a facility undergoing corrective action under an enforcement order [i.e. 3008(h)] should also discuss the specific terms given in 40 CFR 124.10(d). Under 40 CFR 124.10(d) the public notice is required to contain the following information:

$\square$ the facility's name; $\square$ the address of the permit applicant (if applicable);

$\square$ the name and address of agency contact;

a a brief description of the comment procedures;

$\checkmark$ the location and availability of the administrative record;

$\square$ any additional information considered necessary or proper;

$\square$ the date of any previous public notices relating to the permit;

$\square$ the date, time, and place of any public hearings; and

a brief description of the nature of public hearings.

This notice should emphasize the public's role in the remedy selection process. The notice should solicit public comments on all of the corrective measures, as well as on the proposed remedy.

The notice should be published in a widely read section of a major local newspaper of general circulation. Each item developed, received, published, or made available to the public should be available for public inspection and copying at or near the facility or site where corrective action is being considered. In addition to notices in English, notices should be printed in dominant second languages where applicable.

\section{How does the public participate in the remedy selection process?}

The proposed remedy for a facility, along with the key factors that led to its identification, is presented to the public along with a summary of the other alternatives analyzed. Typically the SB, RFI and CMS reports, the administrative record, and the draft permit modification (where applicable) are made available for public comment. DOE has established guidance for public participation that is more expansive than the requirements under RCRA (see references 4, 5, and 6).

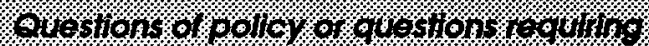

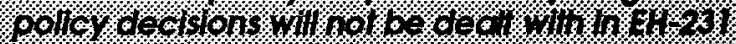

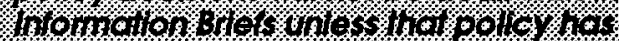

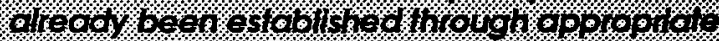
$000100010100 \% 10000 \% 0 \% 01$ $0110 \% 10100000$ mon 1 01010

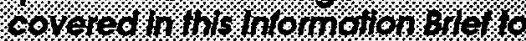

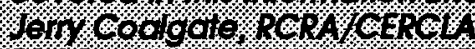

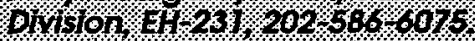

